\title{
Widespread Alveolar Pneumocyte Damage Present
}

National Cancer Institute

\section{Source}

National Cancer Institute. Widespread Alveolar Pneumocyte Damage Present. NCI

Thesaurus. Code 196237.

A morphologic finding indicating the presence of extensive injury of the alveolar pneumocytes in a lung tissue sample. 